\title{
Problematizando a institucionalização da educação popular em saúde no SUS
}

Osvaldo Peralta Bonetti(a)

Muna Muhammad Odeh(b)

Fernando Ferreira Carneiro ${ }^{(c)}$

Bonetti OP, Odeh MM, Carneiro FF. Questioning the Institutionalization of Popular Education in Health in the Unified Health System (SUS - acronym in Portuguese). Interface (Botucatu). 2014;18 Supl 2:1413-1426.

In the context of the implementation of the National Policy of Popular Education in Health, the analysis and reflection on the process of institutionalization of Popular Education in Health in the Unified Health System are deepened. Theunderstanding of the actors embedded in the field of popular education is identified and it stimulates further debate concerning the process of institutionalization, its potentialities, risks and challenges. This article is structured as a qualitative research, which was developed through a semi-structured interviews and literature review. The conclusion of the article is that the institutionalization of popular education in health is a bet that may thrive if the historical background, knowledge, practices and struggles conducted by popular organizations in the health system are recognized and respected.

Keywords: Health Policy. Health System. Education in the health realm. Community Participation.
No contexto da implementação da Política Nacional de Educação Popular em Saúde, aprofundam-se a análise e reflexão sobre o processo de institucionalização da Educação Popular em Saúde no Sistema Único de Saúde. Identifica-se e problematiza-se a compreensão dos atores do campo da educação popular sobre o processo de institucionalização, suas potencialidades, riscos e desafios. Configura-se em uma pesquisa qualitativa realizada por meio de entrevistas semiestruturadas e análise bibliográfica. Conclui que a institucionalização da educação popular em saúde configura-se em uma aposta e que seu êxito dependerá do reconhecimento e respeito à historicidade e ao conjunto dos saberes, práticas e lutas do campo popular na saúde.

Palavras-chave: Política de Saúde. Sistema Único de Saúde. Educação em Saúde. Participação Comunitária.

\footnotetext{
(a) Ministério da Saúde, Departamento de Gestão Participativa (DAGEP). SQN 409, bloco C, apto 207. 70857-030. Brasília DF, Brasil. obonettibr@yahoo.com.br $(b, c)$ Departamento de Saúde Coletiva, Universidade de Brasília. Campus Universitário. muna.odeh@gmail.com, fernandocarneiro. brasilia@gmail.com
} 


\section{Introdução}

Ao refletir sobre a institucionalização da Educação Popular em Saúde (EPS), inicialmente, visitamos sua historicidade, buscando identificar quem são seus atores e o que intencionam.

Neste sentido, a década de 1960 é um marco na caminhada da educação popular, quando profissionais e estudantes engajados na busca da transformação social aproximam-se da cultura popular. Surgem iniciativas como os movimentos populares de cultura, de educação de base, entre outros, nas quais foi possível compreender a cultura popular como uma forma de luta popular, bem como compreender que este processo levaria à transformação das relações de poder e da vida do país ${ }^{1}$.

Já a aproximação da educação popular com a saúde somente veio a se edificar na década seguinte, na qual, inspirados nos conceitos da educação popular, sistematizados inicialmente por Paulo Freire, muitos profissionais de saúde articulados ao movimento da educação popular, à luta pela transformação da atenção à saúde buscaram implementar formas participativas de relação com a população, rompendo com a tradição autoritária dominante que se estabelecia nestes espaços ${ }^{2,3}$.

A sistematização destas experiências em encontros populares veio compor o ideário do que se convencionou chamar de movimento da Reforma Sanitária ${ }^{3}$. Contudo, fortalecendo o cenário das possíveis justificativas para mobilização pela PNEP-SUS, o autor ainda afirma que mesmo com o acolhimento dessas contribuições na VIII Conferência Nacional de Saúde, ocorrida em 1986, o modelo biomédico que está na base do "fosso cultural" entre serviços de saúde e população continuou intocado ${ }^{1}$. Ao analisar o processo da Reforma Sanitária e institucionalização do Sistema Único de Saúde (SUS), o autor afirma ainda ter havido um erro estratégico por parte dos sanitaristas ao conquistarem o SUS, por terem se afastado dos movimentos populares. Assim, desde então o processo político se desloca dos movimentos populares para o âmbito das instituições do Estado, por exemplo, os conselhos de saúde ${ }^{4}$. Reflexão essa que acreditamos ser oportuna ao momento atual do cenário de desafios trazidos pela PNEP-SUS.

Desde então, nos seus mais de 40 anos de história, a EPS tem contribuído como referencial para a configuração de novos espaços de participação popular no contexto do SUS 5 . Processo alimentado pela constituição de novas redes de movimentos e práticas de EPS em todo país, que se configuram em espaços agregadores, sistematizadores e produtores de conhecimentos, conceitos, visões de mundo, atuando como dispositivos fundamentais( ${ }^{(\mathrm{d})}$ para o campo $^{6,7}$.

Segundo Gomes e Merhy ${ }^{8}$, muitas das formulações desenvolvidas pela EPS têm sido agregadas em diversas experiências onde se tenta implementar novas perspectivas de fortalecimento e consolidação do SUS. Percebe-se também que a EPS apresenta uma caminhada crescente junto à gestão do SUS. Contudo, mesmo que se identifique a influência difusa exercida no sistema de saúde, percebe-se que o campo, configurado em um movimento social tão amplo e com razoável acumulação de experiências, tem encontrado muita dificuldade em generalizá-las politicamente ${ }^{3}$.

No que diz respeito à saúde, observa-se que, com a redemocratização do país, a partir de 1980, experiências individuais que atuavam de certa forma clandestinamente, em função do sistema ditatorial, começam a conquistar maior expressão e evidência junto à política de saúde, tornando-se inclusive referência político metodológica de gestões municipais, a exemplo de Recife (2000-2004) e Camaragibe (1996-2004), ambas em Pernambuco e administradas pelo Partido dos Trabalhadores, e no governo estadual de Miguel Arraes (1994-1998), também em Pernambuco ${ }^{2}$. (d) Dentre estes podemos citar a Rede de Educação Popular e Saúde (REDEPOP), a Articulação Nacional de Movimentos e Práticas de Educação Popular e Saúde (ANEPS), - Grupo de Trabalho de Educação Popular e Saúde da ABRASCO, a Articulação Nacional de Extensão Popular em Saúde (ANEPOP), Movimento dos Trabalhadores Sem Terra (MST), entre outros. 
No nível de Governo Federal, o ano de 2003 apresenta-se como um divisor de águas no país, momento em que, fruto de uma grande mobilização dos movimentos sociais, o Partido dos Trabalhadores governa pela primeira vez a Presidência da República com a eleição de Luís Inácio Lula da Silva. Nesse período, encontramos a acolhida da EPS no Ministério da Saúde (MS), ao ser criada a Coordenação Geral de Ações Populares de Educação na Saúde em sua estrutura, integrando a nova Secretaria de Gestão do Trabalho e da Educação na Saúde (SGTES) ${ }^{9}$. Essa iniciativa apresentou-se como um desdobramento da intencionalidade política do movimento em participar do SUS, expressa em 2002 pelos atores da Rede de Educação Popular em Saúde, por meio de uma carta ao Presidente recém-eleito ${ }^{10}$.

Uma das estratégias implementadas neste período foi o apoio à constituição da "Articulação Nacional de Movimentos e Práticas de Educação Popular em Saúde (ANEPS), como um espaço de interlocução entre os movimentos sociais populares e a gestão do sistema" 9 .

No percurso da institucionalização, merece destaque também, o ano de 2008, no qual a Secretaria de Gestão Estratégica e Participativa (SGEP/MS) recebeu a reivindicação, por parte dos movimentos e coletivos nacionais de EPS de qualificação da interlocução com os mesmos, ampliando o espaço de construção coletiva e de apoio institucional às experiências de EPS. Dentre os encaminhamentos sugeridos, foi apresentada a proposta de criação de um grupo de trabalho permanente entre a SGEP e os movimentos e coletivos de EPS(b).

Ao acolhê-la, a Secretaria propôs a implementação do Comitê Nacional de Educação Popular em Saúde (CNEPS), posteriormente instituído pela Portaria GM no 1.256/0911, tendo como objetivo principal a formulação da Política Nacional de Educação Popular em Saúde (PNEP-SUS). Desde então, uma agenda de diálogo tem sido empreendida, confluindo na aprovação em julho de 2012 da Política no Conselho Nacional de Saúde (CNS) e, em maio de 2013, na sua pactuação na Comissão Intergestores Tripartite (CIT) ${ }^{9}$.

Cabe destacar que atualmente a institucionalização da EPS extrapola o setor saúde, sendo que outras áreas também tem buscado fortalecê-la enquanto referencial político-metodológico de suas políticas. No momento presente, o Governo Federal vem promovendo o debate por meio da Secretaria Nacional de Articulação Social da Presidência da República da formulação da Política Intersetorial de Educação Popular.

Assim, na conjuntura atual, muitas indagações emergem, dentre as quais ressaltamos: Qual a compreensão sobre a institucionalização apresentada pelos atores deste processo? Que riscos, desafios e potencialidades são apontados?

Apenas esse leque expositivo já traz dimensões inesgotáveis para o exercício que aqui nos propomos. Porém, enquanto ator que se movimenta no campo, em suas redes e articulações e também protagonista do espaço de gestão da EPS no SUS, me disponho junto aos colegas autores a problematizá-los. Buscamos assim, contribuir com as reflexões sobre a institucionalização da EPS no SUS e identificarmos possíveis contribuições e limitações apresentadas por este processo, na tentativa de identificar nossos acertos e necessárias correções na caminhada.

Instigados pelo contexto da institucionalização, neste artigo buscamos discutir a PNEPS a partir dos resultados encontrados em pesquisa sobre tema. Este trabalho configura-se, assim, em artigo original.

\section{Identificando referenciais teóricos para a reflexão sobre a institucionalização da EPS}

Segundo Gadotti ${ }^{12}$, a educação popular se constitui em um grande conjunto de teorias e de práticas

que tem em comum, nas diversas partes do mundo, o compromisso com os mais pobres, com a emancipação humana. Seguindo sua origem, a EPS é também um compromisso político com as classes populares, com a luta por melhores condições de vida e de saúde, pela cidadania e pelo controle social. Apresenta-se diretamente ligada à valorização e à construção da participação popular, possuindo perspectiva histórica, reconhecendo os pequenos passos e os movimentos das forças sociais em busca do controle de seu próprio destino ${ }^{13}$. 
De acordo com Valla ${ }^{14}$ para os movimentos populares que historicamente vivenciam a educação popular como dispositivo na construção do sentido para sua existência, a mesma traz o pressuposto da integralidade da política. Pois, de maneira geral, lutam no enfrentamento dos múltiplos problemas que aparecem no mundo da vida.

Instigando a importância dos processos instituintes da EPS, Vasconcelos ${ }^{2}$ refere que "não basta alguns saberem fazer, é preciso que o saber seja difundido e generalizado nas instituições de saúde". O autor aponta que temos condições de superar a fase em que as práticas de saúde mais integradas à lógica de vida da população aconteciam apenas em experiências alternativas pontuais e transitórias.

Assim, podemos inferir que as aspirações de fortalecer a institucionalidade da EPS é um processo anterior a 2003 e às próprias experiências governamentais registradas anteriormente, pois se apresentam como um processo político contra-hegemônico, embasado em uma perspectiva integral da política, a qual não pode furtar-se das oportunidades apresentadas pela conjuntura atual.

Para Gadotti12, espera-se hoje da educação popular a "ruptura com seus próprios preconceitos e que não tenha medo, inclusive, de superar-se a si mesma, de renovar-se, refundar-se, fiel ao princípio de buscar respostas para esse novo tempo, aberto a muitas possibilidades de futuro".

Ao problematizarmos a institucionalização da EPS enquanto uma política pública do SUS, é importante aprofundarmos a reflexão sobre a relação entre Estado e Sociedade, pois a tensão entre esses espaços configura-se em elemento estruturante para o exercício da sua compreensão.

Com este intuito, aliados à perspectiva freiriana, revisitamos as formulações de Gramsci, dentre as quais destacamos a centralidade da cultura na práxis política pela transformação do Estado em busca de uma sociedade de todos, onde a liberdade seja, não só um direito, mas uma experiência coletiva ${ }^{15}$.

A aposta na possibilidade de transformação do homem, mesmo que este esteja constantemente sendo condicionado pelo meio, é uma questão transversal entre os mesmos.

Para Gramsci ${ }^{16}$, a sociedade civil é um duplo espaço de luta de classes, expressa contradições e ajustes entre frações da classe dominante e, ao mesmo tempo, nela se organizam também as lutas entre as classes. Logo, não há oposição entre Sociedade Civil e Estado em Gramsci, de certa forma há sim, uma unidade na diversidade ${ }^{17}$. Concorda, assim, com a concepção freiriana que nunca estabeleceu dicotomia entre os espaços Estado e Sociedade Civil, para a qual é inconcebível pensá-los em polaridades absolutas ${ }^{18}$.

Ao apresentar centralidade na subjetividade em sua "filosofia da práxis", Gramsci apresenta o conceito de hegemonia cultural, expondo, sem desmerecer a dimensão econômica, que Marx via como definidora da ordem social, a luta cultural como questão central para as organizações populares ${ }^{19}$.

Consta-se, dessa forma, que o poder de uma classe se define, sobretudo, no campo da cultura, sendo que este não depende tanto do controle do aparelho estatal, mas, antes de tudo, de sua capacidade para dirigir intelectual e moralmente o conjunto da sociedade e para gerar "consensos" condizentes aos seus interesses, sendo o controle do Estado apenas consequência.

Ao expor que o poder se estabelece como soberano, hegemônico, não só pela coerção, mas especialmente pelo consentimento voluntário das classes subalternas e dominadas, Gramsci, longe de buscar a culpabilização das classes populares, veio a desnudar as contradições da hegemonia burguesa, abrindo caminho para compreender a ordem social e, fundamentalmente, as possibilidades para transformá-la ${ }^{19}$.

Conforme a perspectiva apresentada, o "Estado pode ser assumido pela sociedade civil como finalidade intrínseca de sua ação, entendido como espaço de permanente disputa; pode ainda, conforme a capacidade do processo de construção de hegemonia cultural, ser espaço de promoção da justiça social e econômica" 20.

Referindo-se ao setor da educação, Paludo ${ }^{21}$ afirma que o movimento de educação popular que opta pela via da institucionalização em políticas públicas, deve ser mais amplo do que a política propriamente dita. Para a autora, "a construção da educação popular como política pública acompanha, necessariamente, o avanço da refundação do Estado", assim, teria que incidir na explicitação das contradições sociais para se inserir na totalidade do social, processo no qual seus atores teriam que ser necessariamente protagonistas ${ }^{18}$. Apresenta-nos assim, a importância do olhar dialético e problematizador sobre os papéis de cada segmento na relação Sociedade/Estado nos processos de 
institucionalização, a fim de se evitar o aprisionamento da ação política dos movimentos populares que se dedicam a o protagonizar.

Outra referência atual e importante neste contexto é a obra de Boaventura de Sousa Santos que, ao afirmar que vivemos em um mundo de transição paradigmática marcado por perguntas fortes e respostas fracas, propõe a recuperação dos saberes e práticas dos grupos sociais como um "imperativo ético" à sociedade atual. Nesse sentido, apresenta-nos construções importantes como a Sociologia das Ausências, na qual refere ser a racionalidade que alicerça o "pensamento ortopédico ocidental" uma racionalidade indolente, que não reconhece e, por isso, desperdiça muita da experiência social disponível ou possível no mundo22.

$\mathrm{Na}$ formulação da sua Ecologia dos Saberes, o saber só existe enquanto diversidade de saberes, sendo que temos a existência e a possibilidade de uma infinita diversidade destes no mundo. Considera uma exigência atual, a identificação e o rompimento de fronteiras para a construção de saberes mais integrais que atendam com mais efetividade os problemas de nosso tempo ${ }^{22}$.

Santos ${ }^{22}$ também defende a ação, mesmo que em um período de incertezas, de respostas fracas, antes que seja demasiado tarde. Logo, a utopia do presente é o pensamento alternativo de alternativas, ou seja, não desperdiçarmos a infinidade de alternativas que temos acessíveis a partir da radical incerteza destas. Empregarmos assim, outra racionalidade no resgate e construção de saberes, baseada na aposta e não meramente da comprovação de sua eficácia científica como apregoa o pensamento ortopédico.

\section{Metodologia}

O estudo configurou-se como pesquisa qualitativa alinhada ao método freiriano e buscou uma construção dialógica entre pesquisador e pesquisados.

Minayo ${ }^{19}$ afirma que o método qualitativo permite desvelar processos sociais pouco conhecidos, propicia a construção de novas abordagens, revisão e criação de novos conceitos e categorias durante o período de investigação, permitindo a sistematização progressiva de conhecimento até atingir a compreensão do processo em estudo.

O estudo foi desenvolvido por meio da realização de oito entrevistas semiestruturadas com membros do CNEPS e de análise de literatura.

Nas entrevistas, buscou-se identificar e compreender os significados implicados no processo de construção da PNEP-SUS, de acordo com o olhar de seus protagonistas, ressaltando o entendimento sobre institucionalização, riscos, desafios e potencialidades apresentados no processo.

Para tanto, a seleção dos entrevistados contemplou dois atores de cada um dos setores ou espaços de inserção a seguir, buscando atingir a diversidade de olhares e perspectivas: da gestão do SUS, da academia ou pesquisa, dos movimentos populares e do trabalho ou cuidado em saúde.

Esta Pesquisa foi aprovada pelo Comitê de Ética em Pesquisa com Seres Humanos da Faculdade de Saúde da Universidade de Brasília, conforme o Parecer nº 146.691/2012.

\section{A análise das entrevistas}

A transcrição da integralidade das entrevistas foi feita pelo entrevistador, autor da pesquisa, ipsis litteris, preservando-se a originalidade das falas.

Para análise dos dados coletados nas entrevistas foi utilizada como uma referência, a técnica do Discurso do Sujeito Coletivo (DSC). Seguindo as orientações de Lefèvre e Lefrève ${ }^{23}$ sobre o DSC, a escolha das ideias centrais foi realizada com base nos objetivos estabelecidos na pesquisa, na bibliografia e nas falas dos entrevistados, mas, de forma interdependente e interligada à análise dos dados coletados nas entrevistas. Identificou-se como ideias centrais: institucionalidade, potencialidades, riscos e desafios da PNEP-SUS.

Neste percurso, por meio da evidência ou intensidade de aparição, como também pela convergência entre estas nas falas e na bibliografia, elencamos algumas categorias de análise, ou ancoragens como indicam Lefrève e Lefrève ${ }^{23}$, dentre as quais destacamos em relação à institucionalização: parceria, legitimidade, 
perenidade e intersetorialidade; às potencialidades: historicidade, multiculturalidade, saber e cultura popular, protagonismo; aos ricos: não respeito aos princípios; desconhecimento; cooptação; representatividade; regulação das práticas; aos desafios: articulação; trabalho em saúde; reformulação da EPS; ampliação de processo formativos; descentralização; mobilização pelo direito à saúde, intra e intersetorialidade.

\section{Discussão dos resultados: dialogando com as falas dos entrevistados}

\section{Institucionalização da EPS como Política}

Mesmo entendendo a dialogicidade entre o que é instituído e o que é instituinte, apontam que institucionalização é aquilo que torna perene alguma coisa até então periférica, tornando-se acessível de forma universal, garantindo-lhe legitimidade. Ou seja, aquilo que o Estado brasileiro, por meio do SUS, das Secretarias de Saúde, do MS, das Universidades Públicas e demais instituições incorpora no seu conjunto de regras, princípios, costumes e normativas legais.

[...] é aquilo que é torna perene alguma coisa, né, aquilo que é trazê pra dentro do Estado brasileiro.

Contraditoriamente, outro entrevistado, ao trazer a dimensão de parceira no processo de institucionalização, expõe que esta não se tornará algo para sempre, sendo que a parceria será constantemente avaliada, podendo vir o movimento popular e as práticas a se retirar de sua construção.

[...] é uma ideia de parceria, um pensamento de parceria.... porque se o movimento popular estão nessa parceria inseridos, eles não vão dexa que isso aconteça, eu tenha certeza que não vão dexa... porque, por exempro, é, é, o Ministério hoje, pode muda amanhã,... Mas, aí se não apoia, não concorda, vai fica de fora.

Segundo Maltez ${ }^{24}$, citando Burdeau, a institucionalização do poder é a operação jurídica pela qual o poder político se transfere da pessoa dos governantes para uma entidade abstrata - o Estado. Neste sentido, a busca da institucionalização seria o deslocamento do poder ou da decisão política sobre determinado fazer do gestor ou governante, para a Política que seria uma representação do Estado. Com essa, a decisão não estará mais dependente apenas da vontade do gestor, pois, por ter sofrido todo um processo de consenso e negociação para sua aprovação, sendo que demanda processo democrático, institui uma vontade coletiva junto ao arcabouço do Estado.

As falas dos entrevistados apontam também que, ao ser institucionalizada uma Política de EPS em um setor específico, acabará por imputar uma responsabilidade ao Estado, conferindo legitimidade à educação popular nos demais setores das políticas de direito, configurando-se assim, em um processo intersetorial.

Dentro da reflexão sobre a institucionalidade da EPS, merece destaque a leitura apresentada pelos entrevistados sobre as características do Estado brasileiro.

[...] Há uma coisa truculenta de cima pra baixo, vertical, o Estado brasileiro é extremamente autoritário..., a universidade dentro, tem pessoas que lutam pela democracia, mas, dentro das instituições tem muito autoritarismo.

Assim, segundo a fala dos entrevistados, o Estado ainda apresenta características autoritárias, elitistas, sempre em busca da legitimidade na sua relação com a sociedade. Neste sentido, entendemos que, embora haja um governo que apresenta comprometimento com as questões sociais, ainda não conseguimos reconfigurar o Estado de modo geral, a cultura arraigada nas suas múltiplas instituições.

A análise dos três últimos governos, nos mostra grandes conquistas em relação à consolidação da democracia e mobilidade social, com melhoria de vida da população mais pobre. Segundo o último Relatório do Programa das Nações Unidas, o Brasil está entre os 15 países que mais conseguiram 
aumentar o IDH entre 1990 e 2012, alto desempenho em desenvolvimento humano fruto do que o relatório aponta como políticas "certas" 25.

Contudo, novas questões e desafios se colocam. Sader ${ }^{26}$, ainda atual, ao se interrogar sobre qual a natureza dos governos Lula, aponta que não decifrar o enigma do seu significado teria levado a direita a reiteradas derrotas, assim como a esquerda a ser incapaz de se desenvolver, frear o processo de despolitização em curso e se posicionar de maneira correta diante da polarização política e social que vive o Brasil.

Concordando com a afirmativa, Pochmann ${ }^{27}$ refere que as pessoas que melhoraram de renda e emprego são orientadas pelo mercado, favoráveis ao crescimento, mas extremamente conservadoras em valores, favoráveis a pena de morte, por exemplo.

Contraditoriamente, um entrevistado afirma que em relação àqueles que têm acesso à participação, que estão engajados nos movimentos populares construindo políticas durante as últimas três gestões do Governo Federal, este processo tem gerado conscientização e ampliação da habilidade política, para esses o Estado "já não mete medo mais" afirmou.

\section{Potencialidades}

A realização de encontros multiculturais entre segmentos e entre a diversidade de movimentos e práticas, referenciados na leitura crítica da realidade, é apontada como possível contribuição para a ampliação do imaginário popular sobre a saúde, contexto no qual as Tendas Paulo Freire são destacadas como dispositivos importantes.

[...]. Por que pocos momentos que tu encontra vários movimentos sociais, com trajetórias diferentes e vários atores de diferentes espaços...; e se você pode junto, né, amplia esse imaginário do que é saúde,... eu acho que a Educação tem muito a contribui com isso.

A qualificação da relação entre profissionais de saúde, serviços e usuários, como também, do cidadão com a própria saúde é mencionada. Além disso, a possibilidade de ampliar os espaços de participação popular, ao identificar e fomentar novos canais de diálogo, mais identificados com a arte e a cultura popular, são destacados como potencializadores da democracia participativa no SUS. Neste cenário, os círculos de cultura e as rodas de conversa são apresentados como caminhos estimuladores do protagonismo de novos atores no setor saúde.

[...] Qué dizê, cria outra forma de relação, de que a saúde se não se torne apenas médico, enfermeiro, paciente, enfermero, paciente néh, individual, sem nenhuma relação comunitária coletiva.

Às práticas populares de cuidado é atribuída uma grande potencialidade, sendo que contribuem enquanto referencial para as práticas de saúde instituídas no sentido da mudança no modelo de atenção do SUS.

Percebe-se que a EPS poderá vir a contribuir com o protagonismo popular nos processos de cuidado, promovendo maior autonomia. O que se manifestaria em múltiplas dimensões permeando a esfera dos serviços de saúde que também são aparatos ideológicos do Estado, até a produção da saúde de modo mais amplo, impactando inclusive sobre a perspectiva econômica envolvida.

[...] das pessoas se entenderem que ela pode tê autonomia nos seus processos de cuidado e que ela pode exige, também, do Estado, a sua parcela de, de contribuição, né.

Identificamos em falas como "é a reinvenção do SUS", "é a reinvenção de um projeto humanitário", a intencionalidade de construir outro projeto de sociedade, no qual o desenvolvimento seja alicerçado em uma cosmologia mais solidária, mais humana, mais integral e integralizadora, que não desmereça ou marginalize as potencialidades já existentes historicamente acumuladas pelo povo na superação das situações limites enfrentadas no cotidiano. Conflitante assim, com a cultura posta pelo capital, do lucro, 
do individualismo exacerbado, que tem trazido marcas indeléveis à saúde, outra forma de relação entre as pessoas. "[...] o projeto popular apontado por Freire caracteriza-se pelo resgate do histórico de lutas do povo brasileiro, é recuperar a humanidade roubada do povo, construindo uma nova cultura" 28 .

A implementação da PNEP-SUS apresenta potencial para a conquista de uma nova cultura política no SUS, ampliando a democracia participativa, mais identificada e respeitosa com a diversidade da cultura popular brasileira. Construção já em curso no campo das práticas de EPS, mas que agora poderá ser capilarizada, ou seja, possibilitar o alcance aos princípios, valores e "jeitos de fazer" da EPS na vida cotidiana das pessoas. Para esta conquista, é evidente a necessidade de maior investimento público em processos formativos e comunicativos que propiciem aos atores implicados com a implementação da Política, um processo dialógico e pedagógico de fato, promotor de uma rede de interlocutores capazes de contribuir com a sua descentralização junto aos estados e municípios.

Observamos que as intencionalidades manifestadas em relação à PNEP-SUS a configuram identitária da filosofia da práxis, não só por valorizar a dimensão cultural nos processo de cuidado e de participação, como também, por apresentar um referencial político metodológico ao trabalho educativo. Assim como, com a proposta da Ecologia dos Saberes, sendo que PNEPS é compreendida como uma estratégia fortalecedora de um processo multicultural na relação entre os saberes popular e formal. Respondendo ao que seu autor aponta como imperativo ético ao conhecimento na atualidade, destacando o reconhecimento ao saber popular, historicamente relegado na formulação das políticas públicas.

\section{Possíveis riscos}

A inobservância e desrespeito a princípios como o diálogo, a construção compartilhada, a autonomia, a historicidade da EPS na implementação da Política são os primeiros riscos apontados pelos entrevistados. Situação que transformaria a institucionalização apenas em mais uma inovação do campo técnico burocrático do setor, perdendo sua potencialidade como dispositivo promotor de mudanças.

[...] Eu acho que o risco é o esquecimento da história, risos. Existe o risco de tê o esquecimento, então, a gente precisa tá sempre lembrando...

A dificuldade de compreensão sobre o que seja EPS por parte dos trabalhadores de saúde é apresentada por mais de um entrevistado como um risco, podendo vir a ser vivenciada "somente como algo atrelado ao resgate do tradicional". Entende-se que essa afirmativa fortalece a importância da comunicação, dos processos formativos e informativos na implementação da Política.

Ademais, a cooptação dos movimentos populares nesta relação com o governo é colocada de forma dialética, mas referida pela maioria dos atores entrevistados. Alguns a entendem como um grande risco, dentre estes representantes da gestão e dos movimentos populares.

[...] Outro risco é da cooptação não é. Que esses setores, vamos dizê populares, eles comecem a se acomodar numa, numa determinado espaço, numa determinada situação... acho que já, agora já chegamo lá, né, e não precisamos mais, não precisamos mais estar abertos ao novo e essas coisas todas aí né.

Outros acreditam que o processo de politização construído no caminho de institucionalização criou certo "antídoto" a mesma.

[...] Eu acho que se a gente trouxe e tê bem claro a educação popular num de, político, eu acho que não se corre o risco de coopta os movimentos sociais, por que você vai politizando os movimentos também, né.

Apenas um ator do segmento dos movimentos, nega que esta possa ocorrer entre movimentos que têm a práxis da EPS no seu projeto. 
[...]. Mas eu acho que num, não teria risco não, por que se o movimento popular estão nessa parceria inseridos, eles não vão dexa que isso aconteça.

Dentre seus reflexos deletérios, são apresentados por um entrevistado o engessamento das práticas pela burocracia, a perda da perspectiva de movimento que a EPS historicamente construiu, abrandando sua criticidade, uma de suas maiores potencialidades no diálogo com a gestão do Sistema.

Acreditamos que o grau de fragilidade dependerá não somente da força política de cada movimento, mas da identidade com o projeto político da EPS. Logo, movimentos que têm uma práxis referenciada nos princípios da EPS poderão encontrar mais espaços e dispositivos onde possam desenvolver, com criatividade e assertividade, estratégias de apoio, fortalecimento e consolidação de suas experiências.

Um risco apontado por mais de um entrevistado, mesmo não sendo a intencionalidade apontada na Política e por aqueles que estão envolvidos em sua formulação, é o de as iniciativas de fortalecimento das práticas populares de cuidado sejam confundidas com profissionalização e haja a tentativa de um processo de regulação das mesmas.

Sendo um processo participativo, construído em parceria com coletivos e movimentos de educação popular, mesmo que a intencionalidade da PNEP-SUS não seja institucionalizar movimentos e práticas, ainda nos é apresentado o desafio de problematizar cada vez mais sobre qual deverá ser o papel de cada um destes espaços ou atores na implementação da Política? Até onde ir? Em que ações o movimento popular deve centrar suas forças e colocar-se em parceria com o Estado em sua implementação? A beleza e a potência das práticas de EPS possuem íntima relação com a autonomia em que se constroem, profissionalizá-las poderá ser um risco.

Importante também destacar que nas falas dos entrevistados os riscos apresentam dualidade em relação às potencialidades, não de forma contraditória, mas dialeticamente, ou seja, uma possível potencialidade, se não bem trabalhada, pode vir a se configurar em um risco.

\section{Desafios identificados}

Indicada por alguns atores, a necessidade de fortalecimento da relação entre EPS e os segmentos reivindicatórios das políticas de promoção da equidade.

[...] Então, hoje nóis, nós temos, é, reconquistamos esse lugar, né, com o Comitê, com a instituição da Política, mais, a gente tem esse novo desafio que é primero por um lado, fazê esse diálogo, né, com, com essas outras Políticas.

O fortalecimento da EPS nos serviços de saúde é referenciado, apontando-se certa dificuldade para construir coletivamente ações com os profissionais de saúde. "Muitas vezes, não há abertura por parte do Sistema para realizarem tais práticas no seu cotidiano, o que se fortalece pela não consideração desta como produção em saúde", refere um entrevistado.

Merece destaque a demanda exposta por um ator entrevistado de que a EPS "volte a ser elaborada, refletida, formulada", em busca de uma ação mais abrangente em relação à saúde. Nessa retomada, aponta a categoria luta de classes como essencial.

Em relação à gestão, apresentou-se o desafio dessa conseguir fomentar e apoiar os processos educativos/formativos, "o fortalecimento da base", os processos de formação política, os quais identificam-se com a necessária intensificação da mobilização popular pelo direito à saúde

[...] Num primero momento o risco era, ãh, di sê cooptado pela estrutura governamental.... Hoje o risco é tá dentro do Governo e não tê condição de dá continuidade, a dá real legitimidade que é o trabalho de base.

Outro desafio identificado é a implementação descentralizada da Política, ou seja, torná-la institucionalizada em todos os estados e municípios, sendo que há uma diversidade muito grande de gestões, partidos, culturas institucionais, e grande heterogeneidade entre os movimentos populares. 
Destacamos, ainda, o desafio da mobilização pelo direito à saúde, justificado pela afirmativa de que, embora se tenha conquistado a ampliação do acesso por meio da expansão do SUS na atenção básica, ainda são vivenciados inúmeros problemas no cuidado em saúde pela população.

[...] E ai não acabo o problema de jeito nenhum, né. Pelo menos nesse setor não acabo o problema.

$\mathrm{Na}$ análise das críticas e problematizações trazidas nas falas dos entrevistados, evidencia-se a necessária construção da transversalidade entre as políticas já existentes. Além do espaço da gestão participativa, identifica-se que espaços como o da atenção básica, da gestão do trabalho e da educação, onde o enfrentamento junto às instituições de ensino é presente, também devam estar articulados.

\section{Conclusão}

A análise da institucionalização da PNEP-SUS, nos leva a afirmar que o conjunto de saberes, práticas e lutas oriundas do campo popular são elementos que servem de inspiração e referência para os processos de construção da EPS junto à gestão do SUS.

Ademais, as práticas e movimentos de EPS configuram saberes que vão muito além das questões locais ou das áreas temáticas onde se concentram. São capazes não apenas de reivindicar, mas também de propor caminhos inovadores com consistência, qualidade e pertinência ao arcabouço do SUS, de modo a gerar dispositivos e novos marcos institucionais suficientes para fazer avançar seu processo de consolidação, especialmente em relação à sua apropriação por parte da população.

Percebemos que a ação da militância da EPS não se expressa somente pela reivindicação da ampliação do acesso aos serviços e ações convencionais de saúde, consultas, exames, medicamentos. Mas, pela explicitação de que o cuidado em saúde precisa ser diversificado, respeitando, legitimando e fortalecendo as experiências oriundas do saber popular, como as práticas corporais, dos remédios caseiros, da espiritualidade, da alimentação saudável, entre outras.

Neste estudo, pudemos identificar que a institucionalização da EPS requer processo dialógico, construção compartilhada, respeito ao acúmulo popular, reafirmando sua historicidade, reconhecendo os pequenos passos e os movimentos das forças sociais em busca do controle de seu próprio destino. Logo, não dever ser compreendida como um fim em si mesma, mas como uma construção que deve ser paulatina, respeitando os "tempos", as diferenças entre o caminhar dos movimentos e da gestão.

Identificamos que a institucionalização da EPS não é um fato novo, sendo que atores do campo da EPS vem construindo processos instituintes em muitos espaços do Sistema, seja nos serviços, instituições de ensino e até mesmo em experiências em gestões municipais. Nesses, a EPS se organiza construindo diálogos com espaços da sociedade conquistando os aparelhos privados de hegemonia ou contra-hegemonia. É nova, por outro lado, a iniciativa de incorporar a EPS, com seus princípios e práticas, como política pública em nível nacional e inserção transversal em várias outras políticas, especialmente na atenção, na gestão, na formação e na participação popular.

Os referenciais visitados levam a compreensão da importância de "ocupar" o lugar do Estado, disputando-o no sentido de termos políticas que contemplem o saber popular dentre as alternativas para superação das iniquidades e efetivação do direito à saúde. Assim, a institucionalização pode ser percebida como um processo "molhado de ideologia" que busca a conquista de uma ação política mais integral, como historicamente a EPS tem se expressado. Porém, não pode ser resumida apenas à perspectiva formal, e sim, fundamentalmente pela legitimidade do seu processo histórico de transformação cultural na saúde, seguindo o referencial de análise gamsciniano.

Identificamos que a PNEP-SUS se apresenta como fertilizante para a busca do fortalecimento e efetivação de um projeto popular de saúde, explicitando a necessidade de transformar o Estado vigente que determina o modo de fazer saúde. Sua institucionalização se apresenta como uma medida de reparação do Estado brasileiro aos saberes e práticas populares e seus agentes, sendo que foram 
determinantes para a formulação do projeto da Reforma Sanitária, porém, acabaram sendo alijados do processo de implementação do SUS.

Atualmente, embora vivenciemos governos comprometidos com o popular, o Estado brasileiro ainda é condicionado pelas elites, fato que encontra grande expressão no setor saúde. Ainda nos deparamos com posturas coorporativistas em determinadas categorias profissionais que hegemonizam o poder no setor; com uma indústria farmacêutica detentora de poder capaz de definir condutas e posturas ao cuidado; com subfinanciamento do SUS e a existência de planos privados de saúde sendo financiados pelo poder público, por meio dos impostos pagos pela população, para citar alguns exemplos. Estas e outras questões estruturais identificadas nas falas, também precisam poluir a reflexão acadêmica do campo da EPS, ou seja, que as relações de poder instituídas no setor sejam cada vez mais desnudadas e problematizadas a fim de que transformações substanciais aconteçam fortalecendo a luta cultural expressa pelo campo.

Em meio aos muitos desafios, riscos e potencialidades, fica explícita a necessária coragem para esta aposta, como também, o desejo de não perdermos a capacidade de indignação, de que não nos conformemos com a conquista de nosso "pedaço de sistema", do financiamento historicamente sonegado, mas que continuemos partilhando e lutando por um sistema público de saúde de todos os brasileiros.

\section{Referências}

1. Vasconcelos $E M$. Redefinindo as práticas de saúde a partir de experiências de educação popular nos serviços de saúde. Interface (Botucatu). 2001;5(8):121-6.

2. Vasconcelos EM. Educação popular: de uma prática alternativa a uma estratégia de gestão participativa das políticas de saúde. Rev Saúde Coletiva. 2004;14(1):67-83.

3. Stotz EM, David HMSL, Un JW. Educaçãa Popular e Saúde - Trajetória, Expressões e Desafios de Um Movimento Social. Rev APS. 2005;8(1):49-60.

4. Stotz E. Os desafios para o SUS e a educação popular: uma análise baseada na dialética da satisfação das necessidades de saúde. Cadernos de Textos VERSUS. Brasília, DF: Ministério da Saúde; 2004.

5. Pedrosa JIS. Educação popular em saúde e gestão participativa no Sistema Único de Saúde. Rev APS. 2008;11(3):303-13.

6. Bonetti OP, Pedrosa JIS, Siqueira TCA. Educação popular em saúde como política do sistema único de saúde. Rev APS. 2011;14(4):397-407.

7. Oliveira MW. Educação nas práticas e nas pesquisas em saúde: contribuições e tensões propiciadas pela educação popular. Cad Cedes. 2009;29(79):297-306.

8. Gomes LB, Merhy EE. Compreendendo a Educação Popular em Saúde: um estudo na literatura brasileira. Cad Saúde Pública. 2011;27(1):7-18.

9. Ministério da Saúde (BR). Secretaria de Gestão Estratégica e Participativa. Política Nacional de Educação Popular em Saúde no SUS. Brasília, DF: Secretaria de Gestão Estratégica e Participativa; 2013.

10. Rede de Educação Popular e Saúde. Carta: a educação popular em saúde e o governo popular e democrático do Partido dos Trabalhadores. Nós Rede; 2003;(3):6-8.

11. Ministério da Saúde (BR). Portaria $n^{\circ}$. 1256, de 17 de junho de 2009. Institui o Comitê Nacional de Educação Popular em Saúde. Diário Oficial da União. 18 jun 2009.

12. Gadotti M. Estado e educação popular: Desafios de uma política nacional. Seminário sobre Política de Educação Popular; 16 set 2013. Brasília, DF: Secretaria Nacional de Articulação Social da Presidência da República; 2013. 
13. Stotz E. Saúde pública e movimentos sociais em busca do controle do destino. In: Valla VV, Stotz EM, organizadores. Educação, saúde e cidadania. Petrópolis: Vozes; 1994.

14. Valla VV. As classes populares, apoio social e emoção: propondo um debate sobre religião e saúde no Brasil. In: Minayo MCS, Coimbra Jr CEA, organizadores. Críticas e atuantes: ciências sociais e humanas na América Latina. Rio de Janeiro: Fiocruz; 2005.

15. Simionatto I. O social e o político no pensamento de Gramsci. [acesso em: 7 ago. 2012]. Disponível em: http://www.acessa.com/gramsci/?id=294\&page=visualizar.

16. Gramsci A. Concepção dialética da história. Rio de Janeiro: Civilização Brasileira; 1978.

17. Bobbio N. Ensaios sobre Gramsci e o conceito de sociedade civil. 2a ed. São Paulo: Paz e Terra; 2002.

18. Heck S, Pontual P. Pé dentro, pé fora: a experiência brasileira. Rev Latino Amer Caribeña Educ Política. 2013;(37):90-9.

19. Minayo MCS. O desafio do conhecimento: pesquisa qualitativa em saúde. In: Morrow RA, Torres CA, organizadores. Gramsci e a educação popular na América Latina: percepções do debate brasileiro. 10a ed. São Paulo: Hucitec; 2007.

20. Rede de Educação Cidadã. Equipe Talher Nacional. Educação popular como política pública. 2009 [acesso em: 10 nov 2012]. Disponível em: http://www.recid.org.br/ component/k2/item/35-ep-politicapublica.html

21. Paludo C. Educação popular e movimentos sociais na atualidade: algumas considerações. 2009 [acesso em: 10 dez. 2012]. Disponível em: http://www.mmcbrasil. com.br/noticias/040610_ufrgs_conceicao.pdf.

22. Santos BS. A filosofia à venda, a douta ignorância e a aposta de Pascal. Rev Crítica Ciênc Soc. 2008;80:11-43.

23. Lefèvre $F$, Lefèvre AMA. O sujeito coletivo que fala. Interface (Botucatu). 2006;10(20):517-24. http://dx.doi.org/10.1590/S1414-32832006000200017

24. Maltez. J. A. Institucionalização do poder, o que é? [acesso em: 7 out 2013] Disponível em: http://topicospoliticos.blogspot.com.br/2004/10/institucionalizao-do-poder-oque.html.

25. Programa das Nações Unidas para o Desenvolvimento. Relatório de desenvolvimento Humano 2013. Ascensão do Sul: progresso humano num mundo diversificado. New YorK. PNUD; 2013. p. 224

26. Sader E. A nova toupeira: os caminhos da esquerda latino-americana. São Paulo: Boitempo; 2009.

27. Pochmann, M. In Emergentes do país são guiados pelo consumo e emprego. Folha de São Paulo. 26 maio 2012;B2 Mercado.

28. Arroyo M. Paulo Freire e o projeto popular para o Brasil. In: Caldart R, Kolling EJ, organizadores. Paulo Freire: um educador popular do povo. São Paulo: ANCA; 2002. 
Bonetti OP, Odeh MM, Carneiro FF. El cuestionamiento de la institucionalización de la Educación Popular en Salud en el SUS. Interface (Botucatu). 2014;18 Supl 2:1413-1426.

En el contexto de la aplicación de la Política Nacional de Educación Popular en Salud se profundiza en el análisis y la reflexión sobre el proceso de institucionalización de la Educación Popular en Salud en el Sistema Único de Salud. La comprensión de los actores involucrados en el campo de la educación popular es identificada y provoca más debates con respecto al proceso de institucionalización, sus potencialidades, riesgos y desafíos. El presente artículo está estructurado en una investigación cualitativa, que está basada en entrevistas semi-estructuradas y la revisión de la literatura sobre el tema. La conclusión del artículo es que la institucionalización de la educación popular en salud es, en realidad, una apuesta que logrará éxito siempre y cuando la historia, el conocimiento, las prácticas y las luchas conducidas por las organizaciones populares en el ámbito de la salud, sean respetadas y consideradas.

Palabras clave: Política de Salud. Sistema de Salud. Educación para la Salud. Participación comunitaria. 
